\title{
Coconut (Cocos nucifera L.) Lipids: Extraction and Characterization
}

\section{DWI HUDIYANTI ${ }^{1 *}$, MUHAMMAD FUAD AL KHAFIZ ${ }^{2}$ and KHAIRUL ANAM ${ }^{1}$}

${ }^{1}$ Department of Chemistry, Faculty of Science and Mathematics, Diponegoro University-Jl.

Prof. Soedarto, SH 50275 Semarang, Indonesia.

${ }^{2}$ Chemistry Program, Faculty of Science and Mathematics, Diponegoro University-Jl.

Prof. Soedarto, SH 50275 Semarang, Indonesia.

${ }^{\star}$ Corresponding author E-mail: dwi.hudiyanti@live.undip.ac.id

http://dx.doi.org/10.13005/ojc/340268

(Received: January 12, 2018; Accepted: March 25, 2018)

\begin{abstract}
Lipids extraction from dried coconut meat is conducted by maceration using chloroform/ methanol $(2: 1, v / v)$ and partition extraction with $n$-hexane/87\% ethanol $(3: 1)$, and column chromatography. Lipids are analyzed using FTIR, GC-MS, and TLC. Results reveal that dryed coconut meat has $0.04 \%$ phospolipids, $0.22 \%$ of neutral lipids, and $0.04 \%$ of glycolipids and ceramides. Coconut phospolipids consist of phosphatidylcholine (PC), phosphatidylserine (PS), and/or phosphatidylethanolamine (PE) classes for the hydrophilic parts with dodecanoic acid (C12: 0), hexadecanoic acid (C16:0) and octadecanoic acid (C18: 0) as the lipophilic parts.
\end{abstract}

Keywords: Coconut, Phospholipids, Dodecanoic acid, Hexadecanoic acid, Octadecanoic acid.

\section{INTRODUCTION}

Phospholipids (PLs) are amphiphilic lipids obtained in cell membranes of all organisms, organized as lipid bilayers. The PLs discovered are mainly glycerophospholipids (GPLs), which are made of fatty acid residues (FAs) attached to a glycerol backbone by ester formation, a phosphate group and a hydrophilic head group (e.g. choline, serine or ethanolamine). Widespread supplies of industrially cultivated PLs are eggs (chicken and fish), bovine milk, soya, rapeseed, sunflower, coconut, sesame ${ }^{1}$ and jack bean ${ }^{2}$. Each source has a unique composition of distinct phospholipid species and accordingly diverse applications in pharmaceuticals ${ }^{3}$, cosmetics ${ }^{4}$, nutrition, food ${ }^{5}$, and drug delivery ${ }^{6,7}$.

In aqueous media, PLs molecules form aggregate structures by self-assembly course of action $^{8,9}$. Spherical bilayers known as vesicles or liposomes are among of these structures ${ }^{10,11}$. Nowadays liposomes $7,12-14$ and related structures ${ }^{15,16}$ have been actively developed as carriers of bioactive compounds ${ }^{13,14,17-19}$ in various applications ${ }^{13,20}$ since their excellent biocompatibily to natural body environtment ${ }^{6,12,21}$.

This is an 2 Open Access article licensed under a Creative Commons Attribution-NonCommercial-ShareAlike 4.0 International License (https://creativecommons.org/licenses/by-nc-sa/4.0/ ), which permits unrestricted NonCommercial use, distribution and reproduction in any medium, provided the original work is properly cited. 
The characteristic of liposomes is greatly influenced by the physicochemical properties of PLs constituent, such as their molecular species ${ }^{22-25}$. PLs molecular species are determined by their head group (hydrophilic) and hydrocarbon chain types (hydrophobic). These components are diversed base upon their sources ${ }^{3}$. PLs acquired from various natural sources mostly have unique head groups and acyl chains compositions. A judicious stage in lipidomic study is lipid extraction with an suitable organic solvent combination (solvent system) preceding to MS analysis. The accomplishment of the lipid extraction by a certain solvent modification depends upon the partitioning of the lipids into the organic phase and therefore on the lipid composition $^{2,26,27}$.

Previously Hudiyanti et al., ${ }^{25}$ obtained that crude coconut PLs contain sephaline groups whilst the lipophilic parts comprise of dodecanoic acid (C12:0) and octanoic acid (C8:0). In this study we take further steps by purifying these crude PLs with column vacuum chromatography using several eluents to learn more information about the chemistry of coconut PLs. Our new finding is that crude coconut PLs also contained phosphatidylcholine groups and the lipophilic components were hexadecanoic acid (C16:0) and 9-octadecenoic acid (C18:1) as well. Further details of this new finding is presented in the following discussions.

\section{MATERIALS AND METHODS}

\section{Materials}

Dried coconut meat, filter paper, silica gel G60 for column chromatography, chloroform, acetone, methanol, aquabidest, $\mathrm{NaCl}$, the solvent for partition was prepared by partitioning ethanol $87 \%$ with $\mathrm{n}$-hexane $(1: 1, \mathrm{v} / \mathrm{v})$ and the top layer was mark solvent $A$ while the bottom layer was solvent B, TLC plat of silica gel GF254 was washed with chloroform/methanol $(1: 1 \mathrm{v} / \mathrm{v})$, then impregnate with $2.3 \%$ boric acid in absolute ethanol prior used. Spot regents for TLC were dragendorff, ninhidrin, and primulin reagents.

\section{Extraction}

Polar lipids from coconut meat was isolated by method previously presented by Hudiyanti et al., (25). Brieftly, this was prepared by the following procedure. Dried coconut meat powder was macerated with chloroform / methanol (2:1) for 7 days. The filtrate was washed with a $0.9 \%$ of $\mathrm{NaCl}$ solution. Chloroform layer was evaporated to acquired coconut lipid extract. After that $10 \mathrm{~g}$ of coconut lipid extract was dissolved in $45 \mathrm{ml}$ of solvent $A$ and added to $15 \mathrm{ml}$ solvent $B$ in a separating funnel I. The mixture was shaken for 2 minutes. The bottom layer was transferred into a second separating funnel containing $45 \mathrm{ml}$ solvent $A$ and shaken for 2 minutes. The bottom layer containing polar lipids was collected in a vial for further purification while the upper layer was also kept in a separated vial. Fresh $15 \mathrm{ml}$ solvent B was added to the remaining mixture in the first separating funnel and shaken for about 2 minutes. Then the bottom layer is transferred into the second separating funnel containing of fresh $45 \mathrm{ml}$ solvent A. The mixture then shaken and separated as above. The bottom layer and the upper layer were accumulated into the previous separate containers. The procedure was repeated 4-6 times for each $10 \mathrm{~g}$ of coconut lipid extract. The polar lipids containing PLs were purified by column vaccum chromatography as described below.

\section{Purification}

A column containing $50 \mathrm{~g}$ of silica gel $\mathrm{G} 60$ was prepared. A solution of the polar lipid/silica gel $(1: 1, w / w)$ was carefully placed on the silica gel column. For first elution we used chloroform to elute the remaining neutral lipids. Ten $\mathrm{ml}$ eluent was employed for each $10 \mathrm{mg}$ of sample. Second eluent was acetone/methanol $(9: 1, \mathrm{v} / \mathrm{v})$ to elute glycolipids and ceramides (with ratio: $5 \mathrm{ml}$ eluent for $10 \mathrm{mg}$ of sample) and followed by methanol to elute PLs. The coconut lipids was analyzed using FTIR, GCMS, and thin layer chromatography.

\section{RESULTS AND DISCUSSIONS}

Extraction of lipids from dried coconut meat resulted in crude lipids extract, $49.03 \%$ of dried coconut meat. Furthermore the crude lipids extract contained $0.22 \%$ of neutral lipids, $0.04 \%$ of glycolipids and ceramides, and $0.04 \%$ of PLs.

The FTIR spectra of coconut crude lipids extract, neutral lipids, glycolipids and ceramides and PLs are presented in Fig. 1. The major absorption 
peaks of lipids are evidently detectible in the spectrum. The $\mathrm{C}-\mathrm{H}$ stretching vibrations can be identified by peaks at $2924 \mathrm{~cm}^{-1}$ and $2854 \mathrm{~cm}^{-1}$, $\mathrm{C}=\mathrm{O}$ stretching of esters at 1744 to $1728 \mathrm{~cm}^{-1}, \mathrm{CH}_{2}$ bending at $1458 \mathrm{~cm}^{-1}, \mathrm{CH}_{3}$ symetric bending at 1373 $\mathrm{cm}^{-1}, \mathrm{C}-\mathrm{O}-\mathrm{C}$ stretching in esters at $1065-1250 \mathrm{~cm}^{-1}$, and $\mathrm{CH}_{2}$ rocking at 718 and $725 \mathrm{~cm}^{-1}$. Furthermore we find on the crude lipids extract and the PLs spectra several absorption peaks related to phosphate and choline groups. The phosphate group is recognized by $\mathrm{PO}_{2}^{-}$asymmetric stretching peaks at $1226 \mathrm{~cm}^{-1}$ and $1219 \mathrm{~cm}^{-1}, \mathrm{C}-\mathrm{O}-\mathrm{P}$ stretching at $1111 \mathrm{~cm}^{-1}$ and $1064 \mathrm{~cm}^{-1}$ and P-O asymmetric stretching at $887 \mathrm{~cm}^{-1}$ and $817 \mathrm{~cm}^{-1}$. The choline group is recognised by $\left(\mathrm{CH}_{3}\right)_{3} \mathrm{~N}^{+}$asymmetric bending at $1458 \mathrm{~cm}^{-1}$ and $\left(\mathrm{CH}_{3}\right)_{3} \mathrm{~N}^{+}$asymmetric stretching at $972 \mathrm{~cm}^{-1}$ and $972 \mathrm{~cm}^{-1}$. Some of these peaks are slightly shifted from the characteristic band of lipids reported by Wolkers (28), Dean et al., (29) and Forfang et al., (30) it is assumed due to the interfering interaction between neighboring lipids such as acyl chain conformation and formation of hydrogen bonding.

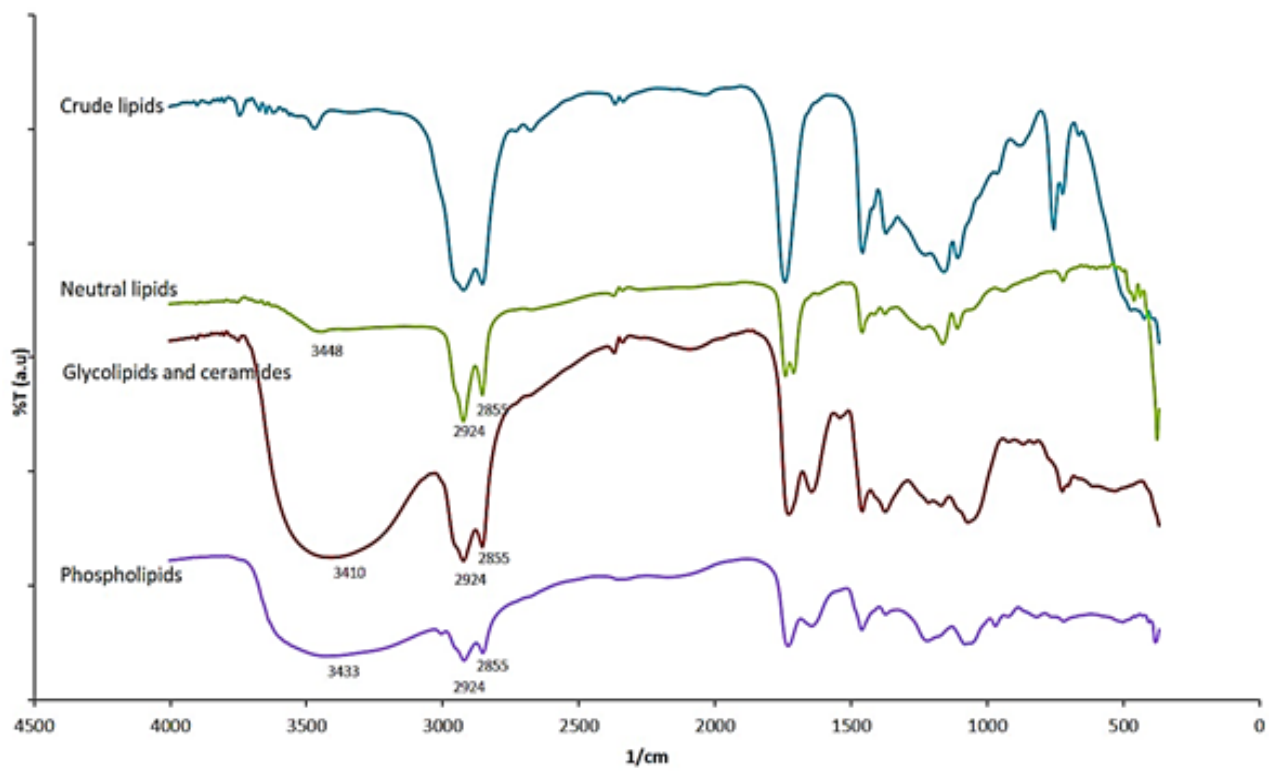

Fig. 1. FTIR spectra of coconut lipids

The acyl chains (lipophilic part) of coconut crude lipid extract, neutral lipids, glycolipids and ceramides, and coconut PLs were analyzed by GCMS and presented on Table 1. Data on Table 1 shows that the composition of acyl chains found in coconut lipids are varied and range from $\mathrm{C} 6$ to C18:2. Crude lipids extract which is directly isolated from coconut meat by extraction with chloroform has the most varied acyl chain length and unsaturation compare to others. The variation decrease as the isolation proceed from crude lipids to PLs. Crude lipids extract has 9 types of acyl chains and 2 of them are unsaturated while the PLs has only 3 types and all of them are saturated i.e. C12:0, C16:0 and C18:0. The dodecanoic acid, $\mathrm{C} 12: 0$, is the most abudant component in all of them. The dodecanoic acid composition in crude lipid extract, neutral lipids, glycolipids and ceramides, and coconut PLs are 45.85\%, 48.13\%, $68.15 \%$, and $90.45 \%$ respectively. The data confirm that dodecanoic acid is the primary acyl chain in all type of lipids in coconut.

TLC analysis on coconut PLs using chloroform/methanol 9:1 as eluent we obtain four spots at $R_{f}$ values $0.115 ; 0.385 ; 0.654$; and 0.808 respectively, see Fig. 2. Dragendorff reagent reveals orange spots for $R_{f}$ value 0.115 and $R_{f} 0.808$ which indicates the present of PLs containing choline groups $\left(-\mathrm{CH}_{2} \mathrm{CH}_{2} \mathrm{~N}^{+}\left(\mathrm{CH}_{3}\right)_{3}\right)$, Fig. 3a. The spot at $\mathrm{R}_{\mathrm{f}}$ value 0.385 turn to purplish red stain when ninhydrin reagent are used as spotting agent, Fig. 3b, which indicates the present of PLs containing free amino groups i.e. serine group $\left(-\mathrm{CH}_{2} \mathrm{CH}_{2} \mathrm{~N}^{+} \mathrm{H}_{3}(\mathrm{COOH})\right.$ or ethanolamine 
$\left(-\mathrm{CH}_{2} \mathrm{CH}_{2} \mathrm{~N}^{+} \mathrm{H}_{3}\right)$ groups. These results suggest phosphatidylcholine (PC), phosphatidylserine (PS), that coconut PLs contain lipid from and/or phosphatidylethanolamine (PE) classes.

Table 1: Acyl chain components in coconut lipids

\begin{tabular}{lcccc}
\hline Acyl chains & \multicolumn{4}{c}{ Area (\%) } \\
& Crude lipids & Neutral lipids & $\begin{array}{c}\text { Glycolipids \& } \\
\text { ceramides }\end{array}$ & PLs \\
\hline C6:0 (hexanoic acid) & & - & - & - \\
C8:0 (octanoic acid) & 0.45 & 17.92 & 3.93 & - \\
C10:0 (decanoic acid) & 6.70 & 5.45 & 0.81 & - \\
C12:0 (dodecanoic acid) & 6.10 & 48.13 & 68.15 & 90.45 \\
C14:0 (tetradecanoic acid) & 45.85 & 2.13 & - & - \\
C16:0 (hexadecanoic acid) & 19.61 & 1.16 & 0.61 & 0.37 \\
C18:0 (octadecanoic acid) & 10.32 & 10.79 & 0.91 & 1.58 \\
C18:1 (9-Octadecenoic acid) & 3.34 & 2.01 & - & - \\
C18:2 (9,12-octadecadienoic acid) & 6.34 & - & - & - \\
\hline
\end{tabular}

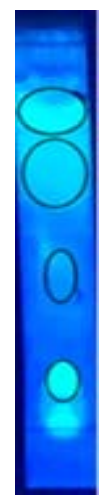

Fig. 2. TLC profile of coconut PLs under UV lamp $\lambda=365 \mathrm{~nm}$

\section{CONCLUSION}

Dryed coconut meat contain $0.04 \%$ phospolipids, $0.22 \%$ of neutral lipids, and $0.04 \%$ of glycolipids and ceramides. Coconut PLs comprise of phosphatidylcholine (PC), phosphatidylserine (PS), and/or phosphatidylethanolamine (PE) classes with dodecanoic acid (C12: 0),

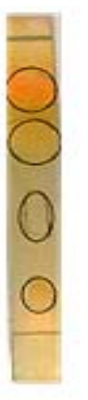
a.
b.

Fig. 3. TLC Profile of coconut PLs (a).Dragendorff stain (b). Ninhydrin stain

octadecanoic acid (C18: 0$)$ and hexadecanoic acid (C16:0) as the lipophilic parts.

\section{ACKNOWLEDGEMENT}

$\mathrm{DH}$ would like to ackowledge the financial support from The Minister of Research, Technology and Higher Education Indonesia via PUPT Research scheme 2016.

\section{REFERENCES}

1. Hudiyanti, D.; Raharjo, T.J.; Narsito, N.; Noegrohati, S. Orient J Chem., 2015, 31, 435-439.

2. Hudiyanti, D.; Arya, A.P.; Siahaan, P.; Suyati, L.
Orient. J. Chem., 2015, 31, 2043-2046.

3. van Hoogevest, P.; Wendel, A. Eur J Lipid Sci Technol., 2014, 116, 1088-10107.

Djekic L.; Krajisnik D.; Micic Z. Tenside 
Surfactants Deterg., 2015, 52, 186-192.

5. Oosting, A.; Kegler, D.; Wopereis, H.J.; Teller, I.C.; van de Heijning, B.J.M.; Verkade, H.J.; van Der Beek, E.M. Pediatr Res., 2012, 72 , 362-369.

6. Li, J.; Wang, X.; Zhang, T.; Wang, C.; Huang, Z.; Luo, X.; Deng, Y. Asian J Pharm Sci., 2015, 10, 81-98.

7. Allen, T.M.; Cullis, P.R. Adv Drug Deliv Rev., 2013, 65, 36-48.

8. Marsh, D. Biophys J., 2012, 102, 10791087.

9. Marsh, D. Biophys J., 2016, 110, 188-196.

10. Hudiyanti, D.; Raharjo, T.J.; Narsito, N.; Noegrohati, S. Indones J Chem., 2012, 12, 57-61.

11. Hudiyanti, D.; Radifar, M.; Raharjo, T.J.; Narsito, N.; Noegrohati, S. J Chem., 2014, 2014, 273084.

12. Bozzuto, G., Molinari, A. Int J Nanomedicine., 2015, 10, 975-999.

13. Dragicevic-Curic, N.; Scheglmann, D.; Albrecht, V.; Fahr, A. Colloids Surf B Biointerfaces., 2009, 74, 114-122.

14. Drulis-Kawa, Z.; Dorotkiewicz-Jach, A. Int J Pharm., 2010, 1-2, 187-198.

15. Kato, S.; Aoshima, H.; Saitoh, Y.; Miwa, N.; J Photochem Photobiol B., 2010, 98, 99-105.

16. Laouini, A.; Jaafar-Maalej, C.; LimayemBlouza, I.; Sfar, S.; Charcosset, C.; Fessi, H. J Colloid Sci Biotechnol., 2012, 1, 147-168.

17. Aisha, A.F.; Majid, A.M.S.A.; Ismail, Z. BMC
Biotechnol., 2014, 14, 23.

18. Birchall, J.C.; Marichal, C.; Campbell, L.; Alwan, A.; Hadgraft, J.; Gumbleton, M. Int J Pharm., 2000, 197, 233-238.

19. Foèo, A.; Gašperlin, M.; Kristl, J. Int J Pharm., 2005, 291, 21-29.

20. Mo, R.; Jiang, T.; Gu, Z. Angew Chem Int Ed., 2014, 53, 5815-5820.

21. Mallick, S.; Choi, J.S. J Nanosci Nanotechnol., 2014, 14, 755-765.

22. Akbarzadeh, A.; Rezaei-Sadabady, R.; Davaran, S.; Joo, S.W.; Zarghami, N.; Hanifehpour, Y.; Samiei, M.; Kouhi, M.; NejatiKoshki, K. Nanoscale Res Lett., 2013, 8, 102.

23. Kawasaki, M.; Yamashita, K.; Noda, M. In: 2016 IEEE SENSORS., 2016, 1-3.

24. Saliba, A-E.; Vonkova, I.; Gavin, A-C. Nat Rev Mol Cell Biol., 2015, 16, 753-761.

25. Hudiyanti, D.; Raharjo, T.J.; Narsito, N.; Noegrohati, S. Agritech., 2012, 32, 23-26.

26. Reis, A.; Rudnitskaya, A.; Blackburn, G.J.; Fauzi, N.M.; Pitt, A.R.; Spickett, C.M. J Lipid Res., 2013, 54, 1812-1824.

27. Axelsson, M.; Gentili, F. PLOS ONE., 2014, 9, 89643.

28. Wolkers, W.F.; In Biological and Biomedical Infrared Spectroscopy., 2009, 272-287.

29. Dean, A.P.; Sigee, D.C.; Estrada, B.; Pittman, J.K. Bioresour Technol., 2010, 101, 4499-4507.

30. Forfang, K.; Zimmermann, B.; Kosa, G.; Kohler, A.; Shapaval, V. PLOS ONE., 2017, 12, 0170611. 